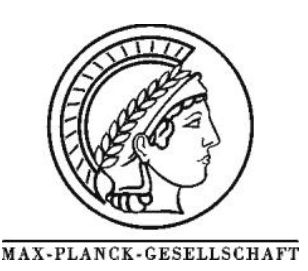

\title{
Investigation of a traditional catalyst by contemporary methods: Parallel electron spectroscopic and catalytic studies on Pt black
}

\author{
Z. Páal ${ }^{a, b, *}$, R. Schlögl ${ }^{\mathrm{b}}$

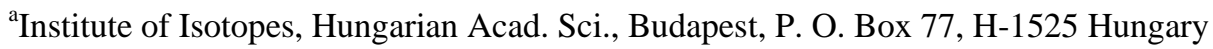 \\ ${ }^{\mathrm{b}}$ Fritz-Haber-Institut der MPG, Faradayweg 4-6, D-14195 Berlin, Germany \\ *Corresponding author: e-mail paal@alpha0.iki.kfki.hu,
}

Available online 10 February 2009

\begin{abstract}
Results of electron spectroscopy (XPS and UPS) of platinum black catalyst measured in various states of the catalyst have been summarized. XPS showed up to almost $50 \%$ carbon and up to $20 \%$ oxygen on a sample stored in air. These, however, had almost no influence on the chemical state of $\mathrm{Pt}$, except for the appearance of minor surface oxide. A Pt purity of $\sim 90 \%$ could be reached by regeneration with $\mathrm{O}_{2}$ and $\mathrm{H}_{2}$. The $\mathrm{C} 1 \mathrm{~s}$ peak contained several components from individual $\mathrm{C}$ atoms to graphitic and polymeric hydrocarbon layers. Thus, the active catalyst was not clean Pt but metallic Pt; the impurities exerting little influence on catalytic activity. Regeneration and deactivation led also to slight structural rearrangement, as detected by XRD. Intentional deactivation with hydrocarbon-hydrogen mixtures was monitored by XPS, UPS and catalytic tests. Correlation was found between catalytic activity and selectivity in hexane reaction and the amount - and also the chemical state - of carbon accumulated during deactivating runs. A short summary of electron spectroscopy of supported Pt catalysts is also given. The main underlying idea regards solid catalyst and reactants as a dynamic system, including also solid-state changes of the former.
\end{abstract}

Keywords: Electron spectroscopy, XPS, UPS, Pt catalyst, Hexane reactions, Catalyst carbonization

\section{Introduction}

The 2007 Nobel Prize in chemistry was bestowed to a physicist, Gerhard Ertl for his studies contributing to our knowledge of heterogeneous catalysts at the atomic level. Heterogeneous catalysts are solid substances that promote reactions in the gas or liquid phase, apparently without suffering any changes. The first definition of catalysis by Berzelius used the words: they are able to ,awaken affinities by their mere presence and not by their own affinity" [1]. The science in the 20th century could not accept his explanation attributing, the mere presence" of a substance to initiate chemical reaction. Adding a phrase ,without being consumed in the process" gave a more exact definition but the interaction of the catalysts with the reacting substances still required explanation on the atomic level. The short history of the development of ideas has been given in the Introduction of the book by Ponec and Bond [2].

Ertl used the newly discovered methods of surface analysis (such as low energy electron diffraction, LEED, electron spectroscopies (Auger-electron spectroscopy, AES; X-ray photoelectron spectroscopy, XPS; Ultraviolet photoelectron spectroscopy, UPS) for studying model catalyst surfaces and their interaction with adsorbed substances [3]. This way, his group described that the structure of adsorbed layers followed the structure of that of the underlying solid [4] and gave also evidence that - for example in ammonia synthesis - the elementary steps involved the dissociation of the diatomic $\mathrm{H}_{2}$ and $\mathrm{N}_{2}$ molecules and the reaction of the chemisorbed atoms in the surface. The full energy diagram of this process [5] has been included in the description of the scientific background of the prize. ${ }^{1}$ Ertl also pointed out that reacting atoms (e. g. N) may also be present in deeper layers of the solid catalyst, and hydrogen may influence how these reactive atoms would come to the surface again where they participate in the catalytic process [6]. It is a pleasure and honor that one of the authors (Z.P.) could work in his group in München studying the interac-

${ }^{1}$ http://nobelprize.org/nobel_prizes/chemistry/laureates/2007/chem adv07.pdf 
tion of $\mathrm{N}_{2}$ and $\mathrm{H}_{2}$ with $\mathrm{K}$-promoted $\mathrm{Fe}$ - and is one of authors of Ref. [6].

Prof. Gerhard Ertl invited Z. P. in 1989 to be a guest scientist in the Fritz-Haber-Institut (FHI) in Berlin, in the group led that time by R. Sch. The research included the study of Pt catalysts prepared and used in Budapest. The present review will summarize the results of almost 20 years. Science has developed during this period - what was high-tech at the end of the $20^{\text {th }}$ century is being replaced by techniques of the $21^{\text {st }}$ century. Some of the recent developments and new directions for future directions will also be summarized, pointing out the validity of the main underlying ideas.

\section{The way from an inorganic preparation to a catalyst.}

„It has been known since the earliest days of the chemistry of metal salt solutions that a number of metals can be formed and precipitated by the action of liquidphase reducing agents" [2]. These "metal blacks" (i.e., fine powders of metals) were used in early catalytic investigations. Sabatier - the 1912 Nobel Laureate in Chemistry, being also the first laureate of catalytic science - did mention „finely divided platinum, sponge or black” in his Nobel lecture as hydrogenation catalyst. ${ }^{2}$ Its use became less and less frequent by the advance of supported Pt catalysts used widely also in industry [7]. On the other hand, single crystals were introduced into scientific investigations $[3,8,9]$. Pt is a typical catalyst of "skeletal" reactions of hydrocarbons $[10,11]$. We studied Pt black catalyst e.g., in dehydrocyclization of hexane and unsaturated $\mathrm{C}_{6}$ hydrocarbons (hexenes, hexadienes and hexatriene) [10,12]. Pt black can be prepared according to Loew, by reducing platinum salts with formaldehyde in strongly alkaline medium ("Pt/HCHO") [13]. Paal [14] used Pt black reduced by hydrazine ("Pt/N"). Pt blacks prepared with both methods have been the subjects of the present study, applying electron spectroscopies, X-ray diffraction (XRD) and transmission electron microscopy (TEM).

The „classical” image of heterogeneous catalyst visualized solid substances which are stable and retain their shape and chemical properties during storage. This has been one of the reasons why Pt and Pd black became commercial products: they ought to have long-term stability during storage or during use in the chemical process. This was more or less true e.g., for liquid-phase hydrogenation at near-room temperatures [14], but heating in the presence of gases (such as $\mathrm{H}_{2}$ or $\mathrm{O}_{2}$ ) resulted in their sintering $[15,16]$. TEM showed the particle size of $\mathrm{Pt} / \mathrm{HCHO}$ to be $\sim 8 \mathrm{~nm}$. Sintering in $\mathrm{H}_{2}$ at $473 \mathrm{~K}$ increased this value to $\sim 30$ $\mathrm{nm}$ while sintering at $\sim 600 \mathrm{~K}$ resulted in particle sizes of $\sim 50 \mathrm{~nm}[15 \mathrm{~b}]$. It turned out that hydrogen was the agent responsible mainly, or exclusively, for this sintering. The

${ }^{2}$ http://nobelprize.org/nobel_prizes/chemistry/laureates/1912/sabati er-lecture.html structure of chemisorbed hydrogen follows the structure of Pt single crystal surfaces giving rise to $\mathrm{H}: \mathrm{Pt}=1: 1$ stoichiometry [17]. Radiotracer studies [18] demonstrated that hydrogen (used as its isotope, tritium) was also absorbed in the bulk of Pt. Sintering could start by formation of a „meniscus” between individual particles [19]. The increase of particle sizes was accompanied also by a considerable drop of the internal lattice stress in both (111) and (100) directions [20]. Reconstruction under the effect of hydrogen has been reported also for single crystals: hydrogen treatment doubled the step height on monoatomic steps of $\mathrm{Pt}(220)$ and (311) surfaces [21]. The line intensities in the X-ray diffractogram of untreated Pt corresponded to that of the JPCD file No 4802. A slight line broadening appeared, due to the small crystallite sizes [22]. Sintering decreased the intensities of higher-angle lines, while subsequent $\mathrm{H}_{2}$ treatments at $473-603 \mathrm{~K}$ reversed this tendency [22,23].

High-resolution TEM of $\mathrm{Pt} / \mathrm{HCHO}$ showed aggregates of elementary particles of 5-12 nm after reduction. These increased up to $20-50 \mathrm{~nm}$ after sintering at $473 \mathrm{~K}$ and reached a size of ca. $100 \mathrm{~nm}$ when the initial $\mathrm{H}_{2}$ treatment took place at $633 \mathrm{~K}$ [20]. Lattice fringes of Pt could be seen both before and after initial sintering (473 K) [24]. The Pt sample, reduced with hydrazine appeared as an aggregate of needle-like crystallites [25]. XRD gave an average crystallite size of $23 \mathrm{~nm}$, with almost zero stacking fault probability. Its sintering was different from that reported for Pt/HCHO: rounding of crystallites was more conspicuous than their agglomeration and crystallite size growth. Peculiar rounded protruding „tongues” appeared after sintering [26].

$\mathrm{X}$-ray diffraction of all samples showed particles sizes of $28-29 \mathrm{~nm}$ in the (111) direction and 25-26 nm in the (200) direction, indicating crystallites "flattened" along (111). The lattice strain was $0.1-0.18 \%$. These samples were measured after regeneration with $\mathrm{O}_{2}$ and $\mathrm{H}_{2}$. The lattice constant $\mathbf{a}_{0}$ was slightly larger after several carbonizing treatments at $603 \mathrm{~K}$ than with regenerated $\mathrm{Pt}(0.3920$ vs. $0.3910 \mathrm{~nm}$ ), indicating some $\mathrm{Pt}-\mathrm{C}$ interactions in the lattice. The value of $\mathbf{a}_{\mathbf{0}}=0.3922$ after the same treatment at $483 \mathrm{~K}$ points to the possible role of surface (or subsurface) hydrogen as one of the reasons of a slight lattice dilatation [27].

The first XPS study of our Pt black was carried out in G. Ertl's laboratory in Munich in 1984 [28]. Several XPS measurements followed in Berlin dealing with the composition and electronic state of Pt catalysts before and after primary sintering and after their purifying treatments with oxygen and/or hydrogen in the preparation chamber of the electron spectrometer $[20,22,-29,30,31]$. The sample holder setup was shown in Ref. [31] and details of the measurements have been summarized in Ref. [32]. Three lots of $\mathrm{Pt}$ black have been investigated: $\mathrm{Pt} / \mathrm{HCHO}$ pretreated with $\mathrm{O}_{2}$ and $\mathrm{H}_{2}$ at 473 and $633 \mathrm{~K}$, respectively as well as $\mathrm{Pt} / \mathrm{N}$ [20,25,29-31]. These samples were stored in air for several months and were occasionally used for hydrocarbon test 
Table 1: Elemental analysis of Pt black catalysts

\begin{tabular}{|c|c|c|c|c|c|}
\hline \multirow[t]{2}{*}{ Sample } & \multicolumn{4}{|c|}{ Composition, atom\% } & \multirow[t]{2}{*}{ Ref. } \\
\hline & $\mathrm{Pt}$ & $\mathrm{C}$ & $\mathrm{O}$ & $\mathrm{K}$ & \\
\hline $\mathrm{Pt} / \mathrm{HCHO}(473)$ untreated & 42 & 44 & 13 & 1 & [29] \\
\hline $\mathrm{Pt} / \mathrm{HCHO}(473)$ reg. $\mathrm{O}_{2} / \mathrm{H}_{2}$ & 62 & 22 & 14 & 2 & [29] \\
\hline $\mathrm{Pt} / \mathrm{HCHO}(473)$ meas. $600 \mathrm{~K}$ & 62 & 22 & 14 & 2 & [34] \\
\hline $\mathrm{Pt} / \mathrm{HCHO}(473) \mathrm{reg} . \mathrm{O}_{2} / \mathrm{H}_{2}, 600 \mathrm{~K}$, meas. $300 \mathrm{~K}$ & 61 & 23 & 14 & 2 & [34] \\
\hline $\mathrm{Pt} / \mathrm{HCHO}(633)$ untreated & 33 & 47 & 19 & 1 & [29] \\
\hline $\mathrm{Pt} / \mathrm{HCHO}(633)$ reg. $\mathrm{O}_{2} / \mathrm{H}_{2}$ & 51 & 29 & 19 & 2 & [29] \\
\hline $\mathrm{Pt} / \mathrm{N}$ untreated & 39 & 28 & 27 & - & {$[30]$} \\
\hline $\mathrm{Pt} / \mathrm{N}$ reg. $\mathrm{O}_{2} / \mathrm{H}_{2}$ & 68 & 15 & 17 & - & {$[30]$} \\
\hline $\mathrm{Pt} / \mathrm{HCHO}$ fresh, unsintered & 67 & 24 & 9 & - & {$[24]$} \\
\hline $\mathrm{Pt} / \mathrm{HCHO}(473)$ fresh, sintered & 73 & 18 & 9 & - & {$[24]$} \\
\hline $\mathrm{Pt} / \mathrm{HCHO}(473)$ reg. $\mathrm{O}_{2} / \mathrm{H}_{2}$ & 77 & 18 & 5 & - & {$[24]$} \\
\hline $\mathrm{Pt} / \mathrm{N}$ (unsintered) & 67 & 18 & 15 & & {$[22]$} \\
\hline $\mathrm{Pt} / \mathrm{N}(473)$ sintered & 64 & 12 & 24 & & {$[22]$} \\
\hline $\mathrm{Pt} / \mathrm{N}(473) \mathrm{UHV}, 60 \mathrm{~h}$ & 64 & 12 & 24 & & {$[22]$} \\
\hline $\mathrm{Pt} / \mathrm{N}(473) 270 \mathrm{mbar}_{2} 300 \mathrm{~K}$ & 64 & 12 & 24 & & {$[22]$} \\
\hline $\mathrm{Pt} / \mathrm{N}(473)$ & 75 & 12 & 13 & & {$[26]$} \\
\hline $\mathrm{Pt} / \mathrm{N}(473) \mathrm{O}_{2} /$ at $473 \mathrm{~K}$ & 89 & 9 & 2 & & {$[26]$} \\
\hline $\mathrm{Pt} / \mathrm{N}(473) \mathrm{H}_{2} /$ at $473 \mathrm{~K}\left(\right.$ after $\left.\mathrm{O}_{2}\right)$ & 87 & 12 & 1 & & {$[26]$} \\
\hline $\mathrm{Pt} / \mathrm{N}(473) \mathrm{O}_{2} /$ at $603 \mathrm{~K}$ & 92 & 6 & 2 & & {$[26]$} \\
\hline $\mathrm{Pt} / \mathrm{N}(473) \mathrm{H}_{2} /$ at $473 \mathrm{~K}\left(\right.$ after $\left.\mathrm{O}_{2}, 603 \mathrm{~K}\right)$ & 88 & 10 & 2 & & [26] \\
\hline
\end{tabular}

reactions [20,33]. Early results were measured and published in the beginning of the 1990's years.

Untreated Pt was contaminated by oxygen and carbonaceous species adsorbed unavoidably from polluted urban air to a degree that Pt became a minority surface component (,untreated" samples). That can be expected also for commercial metal blacks - Pt or Pd. Electron microscopy confirmed the presence of carbon on Pt black ( $\mathrm{Pt} / \mathrm{HCHO})$ before its first contact with hydrocarbon reactants [24]. Figure 1 shows a micrograph of an untreated $\mathrm{Pt} / \mathrm{N}$ with a - more or less amorphous - carbon overlayer on a Pt particle with visible lattice image.

Selected sample compositions are shown in Table 1. There were notable differences between the purity of $\mathrm{Pt}$ black samples of different preparation and subjected to different pretreatments: $\mathrm{Pt} / \mathrm{N}$ and $\mathrm{Pt} / \mathrm{HCHO}(473)$ could reach purity better than $60 \%$, but the $\mathrm{Pt}$ content of $\mathrm{Pt} / \mathrm{HCHO}(633)$ was hardly better than $\sim 50 \%$. Even increasing the regeneration temperature up to $800 \mathrm{~K} \mathrm{did} \mathrm{not} \mathrm{im-}$ prove this value [30]. When the XP spectrum was recorded from a $\mathrm{Pt} / \mathrm{HCHO}(473)$ sample kept at $600 \mathrm{~K}$ during measurement, the Pt percentage was just above $60 \%$ [30,34], and remained so after repeated $\mathrm{O}_{2} / \mathrm{H}_{2}$ regenerations. The $\mathrm{O}$ content dropped to $\sim 10 \%$ even after regeneration with $\mathrm{O}_{2}$. $\mathrm{H}_{2}$ treatment after $\mathrm{O}_{2}$ increased the percentage of surface carbon, supporting the assumptions of Pt restructuring under the effect of treatments, in particular, contacting it with 


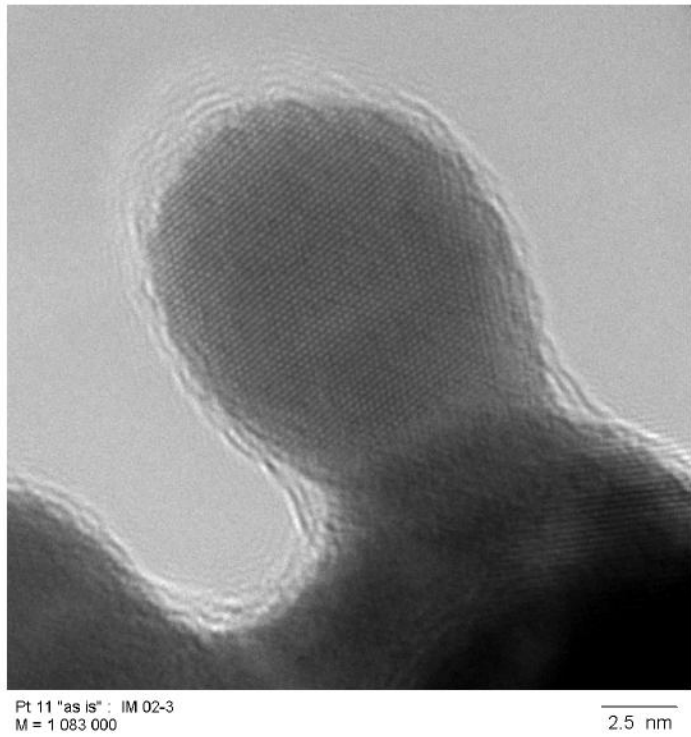

Fig. 1: Electron micrograph of a Pt/N sample sintered at $473 \mathrm{~K}$ and taken out of the electron spectrometer after XPS and UPS without any further treatment.

$\mathrm{H}_{2}$ at higher temperature. This must have promoted segregation of subsurface carbon to surface regions.

Figure 2 depicts $\mathrm{Pt}$ 4f peaks in different states. The difference spectra indicate the presence of small amounts of surface PtO $(\Delta \mathrm{E} \sim 2.4 \mathrm{eV})$ and "chemisorbed $\mathrm{O}$ " $(\Delta \mathrm{E} \sim 0.8$ eV) [35] appeared on the difference spectrum, as shown also by Fig. 2 in Ref. [29]. Both $\mathrm{Pt} / \mathrm{N}$ and $\mathrm{Pt} / \mathrm{HCHO}$ showed Pt predominantly in the metallic state after regeneration removing excess surface $\mathrm{C}$ and $\mathrm{O}$ impurities [29,30]. The He I spectrum [30] compared well with that measured on a clean Pt foil [36] (although with a lower Fermi-edge). Catalytically active platinum is, thus, in the metallic state, but it is not necessarily (or better to say, not typically) chemically clean platinum [29,30].

Other preparations, avoiding contamination during sintering led to somewhat cleaner metal black: the lower half of Table 1 includes preparations from the late 1990's. High-temperature treatments with $\mathrm{O}_{2}$ (like those applied for regeneration after hydrocarbon reactions [20,25]) could increase the purity of Pt up to $\sim 90 \%$. A customary regeneration temperature was $603 \mathrm{~K}$ [30]. In typical runs (when reactions and regeneration followed each other), even regenerated catalysts may contain $20-25 \% \mathrm{C}$ on its surface. This agrees well with earlier assumptions. Sárkány [37] defined three stages in the lifetime of a working Pt catalyst, assuming reactions which need hydrogen atmosphere; accordingly, a purified $\mathrm{Pt}$ is in the "Pt-H" state and its activity concentrates on $\mathrm{C}-\mathrm{C}$ bond rupture, i.e., it forms fragments, mainly methane. After accumulation of a certain amount of carbon on the surface, - as hydrocarbonaceous deposits - a "Pt-C-H" state arises. $\mathrm{Pt}$ in this state has a steady-state activity in nondegradative hydrocarbon reactions. Accumulation of surface carbon (and its dehydrogenation) leads to a deactivated "Pt-C" state. The assumption

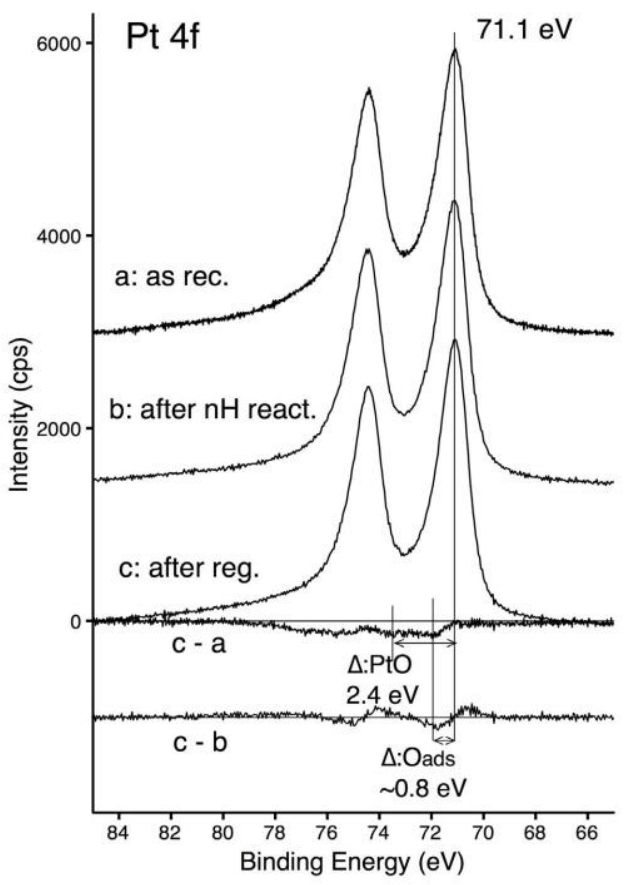

Fig. 2: $\mathrm{Pt} 4 \mathrm{f}$ lines of $\mathrm{Pt} / \mathrm{N}$ in the "as received" state as well as after hexane reaction and regeneration with $\mathrm{O}_{2}$ and $\mathrm{H}_{2}$ at $603 \mathrm{~K}$.

of carbon on working catalysts agrees well with earlier studies on disperse catalysts [38] as well as on single Pt crystals [39] assuming even the presence of "beneficial" carbon during reaction [40]. Ref. [30] included a model for a polycrystalline $\mathrm{Pt}$ covered partly with carbonaceous species, with $\mathrm{OH} / \mathrm{H}_{2} \mathrm{O}$ also present.

C 1s spectra evidencing the development of the carbonaceous overlayer were shown in Ref. [22]. The rather diffuse carbon overlayer (see electron micrograph in Figure 1) consisting of $\mathrm{C}$ in various chemical states transformed into an overlayer of graphite (BE $\sim 284.5 \mathrm{eV}$ ) and "chain" carbon (BE $284.1 \mathrm{eV}$ ) in UHV, with CO chemisorbed from the residual gas. After $\mathrm{H}_{2}$ treatment, graphitic carbon prevailed.

\section{Surface and bulk changes of a catalyst interacting with the reactants.}

\subsection{What can we learn about the interaction of a hydrocarbon reactant and Pt black?}

Somorjai [Ref. 41, p. 461] distinguished three classes of studying surface chemistry and catalysis:

1. Chemisorption, structure and surface bonding at low pressures $\left(<10^{-4}\right.$ mbar $)$.

2. Surface reactions on small area crystals, foils, thin films at high pressures $\left(10^{3}-10^{5} \mathrm{mbar}\right)$. 
3. Reactions on dispersed catalysts at high pressures $\left(10^{3}-10^{5}\right.$ mbar $)$.

Reaction studies with Pt black were carried out in the pressure range of 13-53 mbar, in the presence of excess $\mathrm{H}_{2}$ up to $\sim 600$ mbar, analogous to Class 3 . Surface spectroscopy, in turn, took place under ultrahigh-vacuum (UHV) conditions (Class 1). The present studies involved two series of experiments. One was carried out in a specific electron spectrometer equipped with a preparation chamber making possible to pretreat the sample at pressures up to a few hundred mbar with gases as well as vapors of the reactants. The sample was thereafter evacuated and shifted into the spectrometer where XPS, UPS (and also ion scattering spectroscopy, ISS) studies followed. In another series, the catalyst was exposed in a batch reactor to exactly the same pretreatments as done in the preparation chamber. These were followed by test reactions. The catalyst was not exposed to atmosphere between pretreatment and spectroscopy and between pretreatment and test reaction, respectively. This way, "quasi-in-situ" experiments were carried out permitting one to judge the surface state and composition of the catalyst meeting the test reactant. Thus, we combined all three classes: results of electron spectroscopy (Class 1) were compared with results of catalytic measurements involving a disperse catalyst (Class 3) which, however, was an unsupported sample (Class 2), therefore closer to the practically useful catalysts. Experiments with supported catalysts will also be mentioned in due course.

Skeletal reactions of $\mathrm{C}_{6}$ hydrocarbons have been selected as models, including dehydrocyclization to aromatics, $\mathrm{C}_{5}$-cyclization to cyclopentanes, skeletal isomerization, fragmentation and dehydrogenation to alkenes $[10,42]$. The formation of an aromatic ring takes place by successive dehydrogenation of the alkane to alkene, alkadiene (possible also triene). The cis-isomers of dienes and trienes produce a six-membered ring by a facile ring closure reaction [12], preferable on sites containing three Pt atoms in hexagonal symmetry $[43,44]$. Trans-isomers, in turn, are precursors of carbonaceous deposits, hence cause deactivation. The trans $\leftrightarrow$ cis isomerization requires hydrogen on the metal surface [12]. Isomerization and $\mathrm{C}_{5}$-cyclization take place on two-atom $\mathrm{Pt}$ ensembles, both requiring ample hydrogen [10,42]. Scheme 1 (adapted after Ref. [45]) summarizes the catalytic processes.

XPS monitored Pt 4f, $\mathrm{C} 1 \mathrm{~s}$ and $\mathrm{O}$ 1s peaks before and after contacting Pt with hydrocarbons. Pt $4 \mathrm{f}$ peaks after different treatments were not processed further, since what was stated in section II was valid in each case: Pt remained in metallic state. The peak maximum was $71 \mathrm{eV}$, with shifts of typically $\pm 0.1 \mathrm{eV}$, even after weeks or months. After excessive oxygen treatments, $\mathrm{PtO}$ and/or $\mathrm{O}_{\text {ads }}$ may be present (cf. Fig. 2). Oxygen may also be present as "oxidized C" species [30]. The C 1s peak was decomposed into individual components. Various possible carbon species have been listed with $\mathrm{BE}$ values between 282.5 and $288.5 \mathrm{eV}$

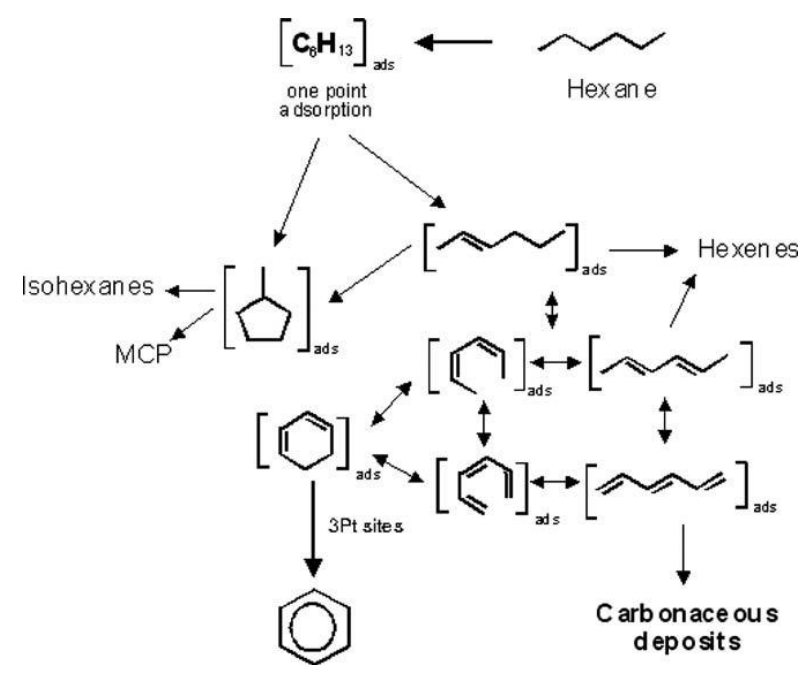

Scheme 1: Scheme of skeletal reactions of hexane, showing the "stepwise aromatization" reaction route in detail. Adapted after Ref. [Fehler! Textmarke nicht definiert.]

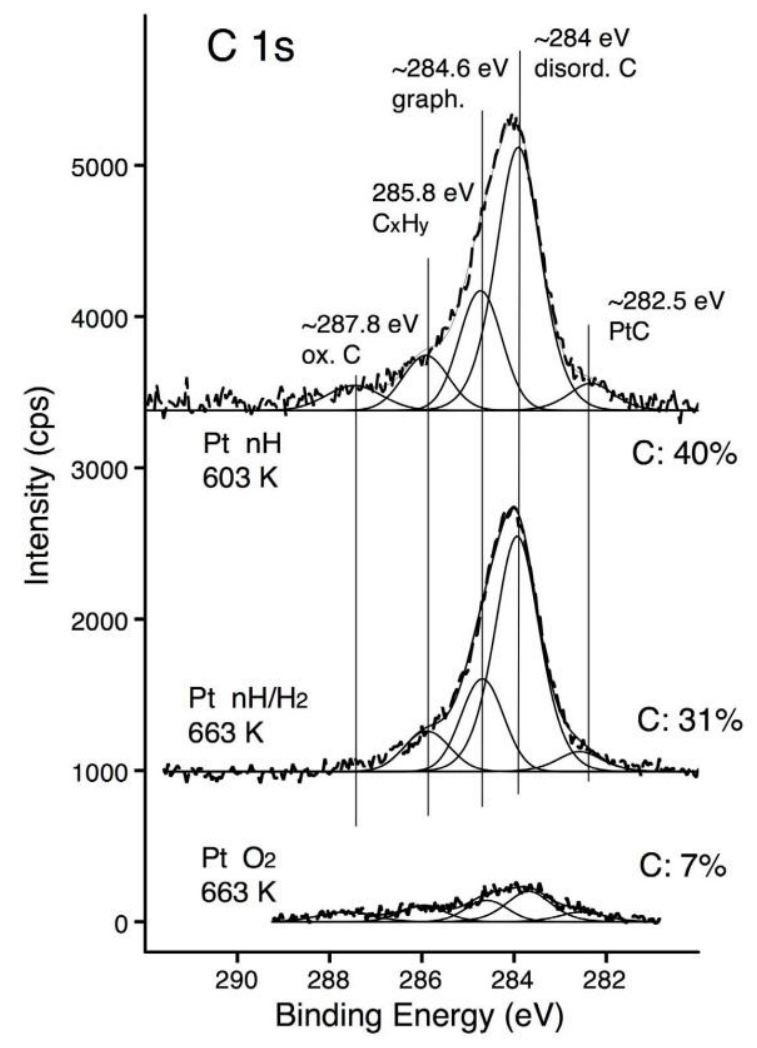

Fig. 3: Fitting of the $\mathrm{C} 1 \mathrm{~s}$ line on Pt black after three different treatments.

[24]. The most successful fitting procedure contained just 5 components with fixed Gaussian-Lorentzian ratios and peak half-width, but letting the fitting procedure find the maximum BE values for each component. Three fittings are shown in Figure 3 with rather different $\mathrm{C}$ 1s percentages. "Disordered" C (BE $284.1 \mathrm{eV})$, representing an unsat 


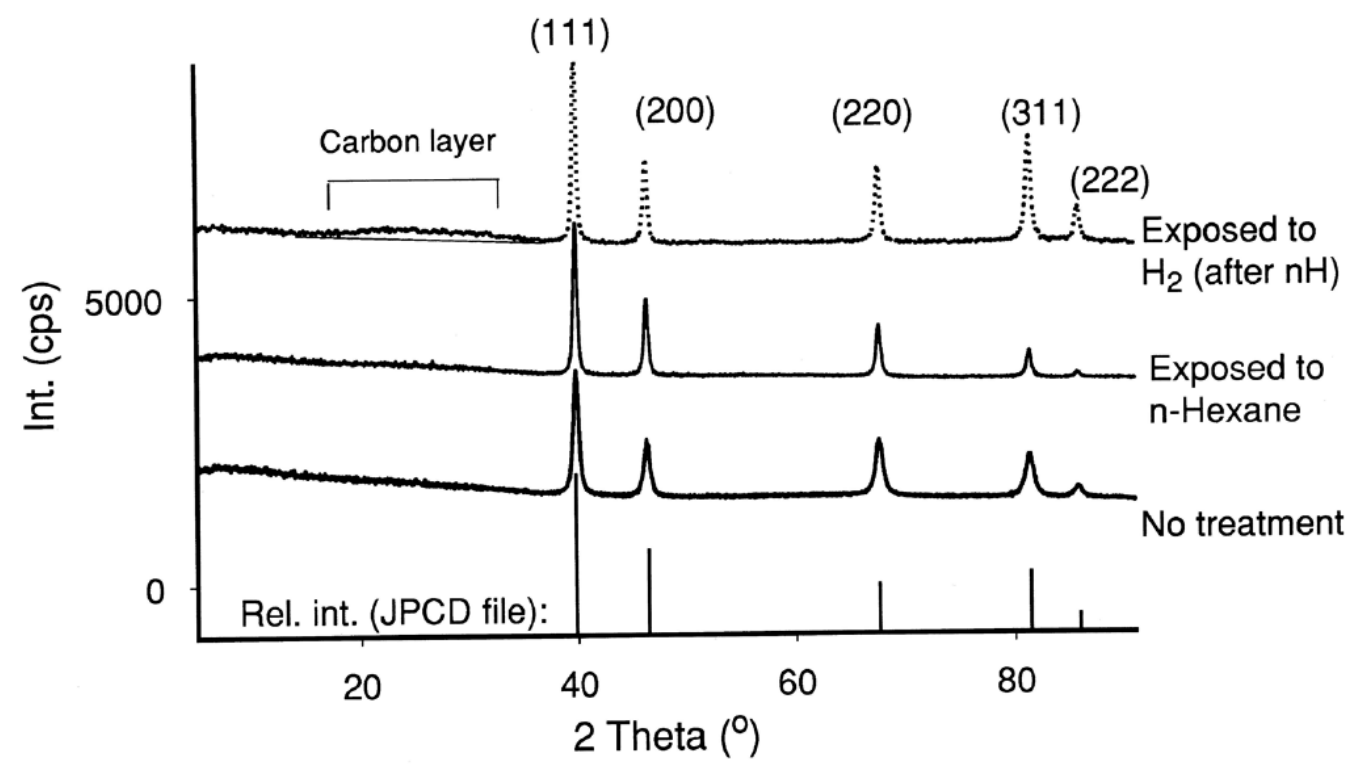

Fig. 4: XRD lines of Pt black after various treatments (adapted after Ref. [46]).

rated surface polymer, such as dimers, tetramers etc. of trans-polyenes (cf. Scheme 1) predominates in each spectrum, followed by graphite $(\mathrm{BE} \sim 284.6 \mathrm{eV})$ and a polymer of assumedly saturated character, " $\mathrm{C}_{\mathrm{x}} \mathrm{H}_{\mathrm{y}}$ " $(\mathrm{BE} \sim 285.6 \mathrm{eV})$. Low amounts of oxidized $\mathrm{C}(\mathrm{BE}>286 \mathrm{eV})$ and "PtC" (carbide and/or isolated $\mathrm{C}$ atoms, $\mathrm{BE} \sim 283 \mathrm{eV}$ ) are also present.

The structural rearrangement of Pt during hydrocarbon treatments was also observed by XRD [22,23,46] (Figure 4). The relative intensities of individual diffraction peaks of an untreated $\mathrm{Pt}$ (just sintered) corresponded roughly to the intensity ratios of a perfect crystal, ${ }^{3}$ although higher-order reflections (311), (222) had somewhat lower intensities. A definite rearrangement can be observed after exposure to $\mathrm{nH}(603 \mathrm{~K})$ : the (111) intensity increased and (220), (311), (222) decreased. A subsequent regeneration with $\mathrm{O}_{2}$ and $\mathrm{H}_{2}$ at $603 \mathrm{~K}$ increased the (111) as well as the (311) reflections, in agreement with Maire et al. [47] reporting the doubling of the height of (311) steps under hydrogen effect and Somorjai's more general concept of "flexible surfaces" [47]. The presence of "overlayer-type carbon" corresponds to the main peak of the fitted C 1s line and appeared also in UPS [46].

\subsection{Systematic studies on the effect of tempera- ture and $\mathrm{H}_{2}$ pressure on Pt deactivation}

The combined electron spectroscopic and catalytic study of the Pt catalyst including its purification, then exposing it to a hydrocarbon/hydrogen mixture at various pressures and temperatures have been reported recently [26,48]. Saturated and unsaturated $\mathrm{C}_{6}$ hydrocarbons were selected as models (cf. Scheme 1). It is expected that (i) trans-trans-2,4-hexadiene (HD) will lead to accumulation of more surface carbon and will cause a stronger deactivation than hexane $(\mathrm{nH})$; (ii) with more hydrogen present, lower deactivation and less carbon will remain; (iii) at higher temperature less residual surface hydrogen can be expected, therefore the deactivating procedures will be enhanced. The reactions during deactivation treatment as well as a subsequent test reaction (13 mbar $\mathrm{nH}$ plus 160 mbar $\mathrm{H}_{2}$ at $603 \mathrm{~K}$ ) were monitored.

A mixture of $\mathrm{nH}: \mathrm{H}_{2}=13: 80$ as the deactivating agent transformed mainly into fragments and saturated $\mathrm{C}_{6}$ products: isomers plus methylcyclopentane (MCP). Some benzene and traces of hexenes were formed at 483 and $543 \mathrm{~K}$ [48]. Conspicuously less isomers and MCP were produced at $603 \mathrm{~K}$ and their amount was nil at $663 \mathrm{~K}$ where benzene and fragments were the main products. The turnover frequencies (TOF) were, at the same time almost equal from 543 and $663 \mathrm{~K}$ [48]. The TOF of HD reaction was higher by a factor of ten in the whole temperature range. It was hydrogenated to hexane with almost $100 \%$ selectivity at 483 and $543 \mathrm{~K}$, but hexenes and isomer hexadienes prevailed at 603 and $663 \mathrm{~K}$, with a benzene selectivity of as low as $\sim 10 \%$. The same tendency was observed in the subsequent test runs with $\mathrm{nH}+\mathrm{H}_{2}$. The residual activity was 63 to $75 \%$ after deactivation at $483 \mathrm{~K}$. These values dropped to $15-18 \%$ at $663 \mathrm{~K}$ (the lower values belonging to deactivation with $\mathrm{HD}$ ). The selectivity changes in the test runs were much more pronounced after deactivation with HD. The amount of carbon on a regenerated $\mathrm{Pt}$ was $15 \%$. This increased to $31 \%$ after deactivation with $\mathrm{nH}$ and up to $45 \%$ after HD treatment. Difference spectra showed an excess of three C 1s components after handling with HD; "chain" carbon $(\sim 284.1 \mathrm{eV})$, graphite $(\sim 284.6 \mathrm{eV})$ and $\mathrm{C}_{\mathrm{x}} \mathrm{H}_{\mathrm{y}}$ $(\sim 285.6 \mathrm{eV})$. Less graphite appeared after pretreatment at $483 \mathrm{~K}$ with $\mathrm{HD}$ than with $\mathrm{nH}$ (HD being hydrogenated to hexane with $\sim 95 \%$ selectivity).

\footnotetext{
${ }^{3}$ JPCD file No. 4802
} 


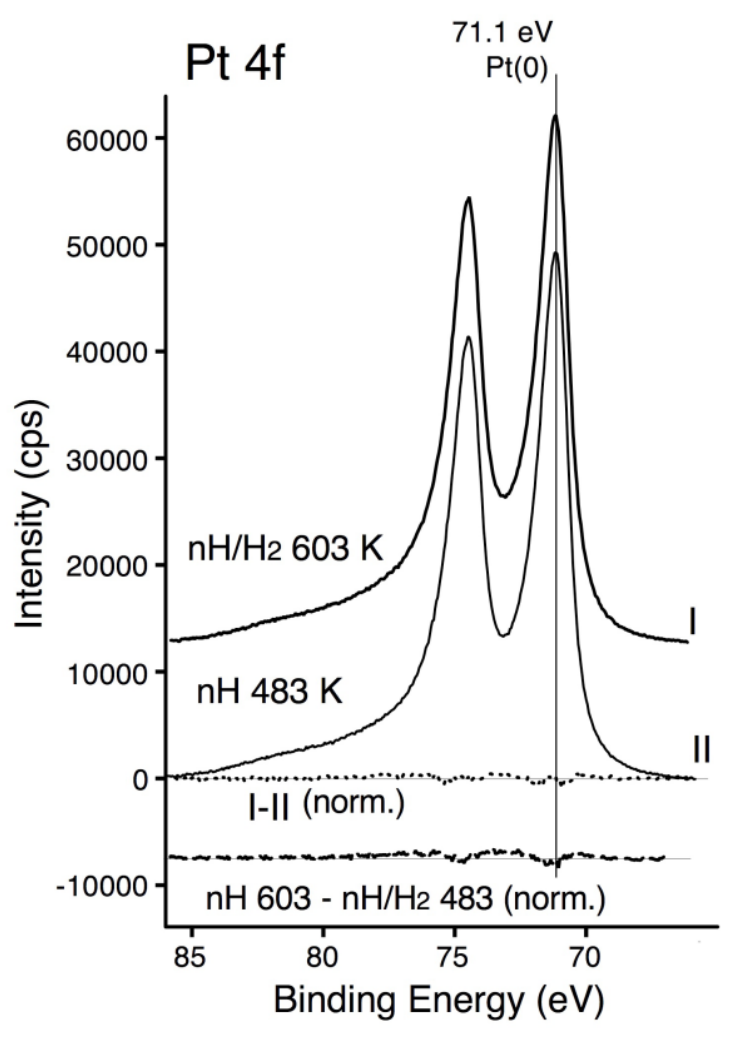

Fig. 5: Pt $4 \mathrm{f}$ peaks measured after different treatments described in Figure 5.

Parallel experiments carried out with supported catalysts $\left(\mathrm{Pt} / \mathrm{SiO}_{2}\right.$ : EUROPT-1; Pt/graphite nanofiber and $\left.\mathrm{Pt} / \mathrm{CeO}_{2}\right)$ showed similar tendencies in deactivation. They could not be monitored by electron spectroscopy, but the similarity of catalytic behavior indicates that analogous processes took also place on their Pt particles, confirming H. S. Taylor's opinion, that the catalytic reaction can be the best diagnostic way to obtain information on the active surface. The effect of surface carbon was different: "beneficial" after pretreatment at $483 \mathrm{~K}$ (as defined by Menon [40]); the deactivation was "nonselective" (producing somewhat more hexene but leaving other selectivities almost intact), "selective" (more hexene) and "severe" (hexene selectivities increase up to 30 times, the others dropped to $30-50 \%$ of their original values). Interesting to note that benzene selectivity was less affected even after the loss of $90 \%$ of the original activity [48]. This indicates that even severe carbonization left some three-atom Pt sites suitable for aromatization.

Another study [26] used $\mathrm{nH}$ as deactivating agent mixed with different amounts of hydrogen, at two temperatures: 483 and $603 \mathrm{~K}$. The Pt $4 \mathrm{f}$ peak measured after treatments of different severity (Figure 5) indicated metallic $\mathrm{Pt}$ in each case: after deactivation with $\mathrm{nH}$ or $\mathrm{nH} / \mathrm{H}_{2}$ at various temperatures. The peak shapes resembled to $\mathrm{Pt} 4 \mathrm{f}$ observed after regeneration with $\mathrm{O}_{2}$ and $\mathrm{H}_{2}$ (cf. Figure 2). This confirms the presence of "overlayer-type carbon" with hardly any electronic interaction between $\mathrm{Pt}$ and $\mathrm{C}$, in agreement with the He II spectra after deactivating treatments at 483 and $603 \mathrm{~K}$ (Figure 6) confirm this. The Fermi-edge intensity was still rather high even after this treatment, in accordance with the Pt $4 \mathrm{f}$ peaks showing a metallic character even after deactivation. He II spectra normalized at the Fermi-edge are rather similar. The electron structure (a sharp Fermi-edge) remained after each treatment. The normalized difference spectra [treated $\mathrm{Pt}-\mathrm{Pt} / \mathrm{reg}$.] show hardly any electron depletion in the low $\mathrm{BE}$ range and "overlayer-type carbon peaks" in the BE range of $\sim 5-11 \mathrm{eV}$ (observed also in other experiments [22,23,46]). More marked differences appear upon normalization at $13 \mathrm{eV}$ after treatment with $\mathrm{nH}=53 \mathrm{mbar}$. Electron depletion could be seen in the low BE region of Pt and a C $2 p$ peak appeared (at $\sim 3 \mathrm{eV}$ ) on the difference spectrum (cf. Fig. 5 in Ref. [26]).

C 1s difference spectra and parallel column diagrams of the selectivities measured in test runs are shown in Figure 7. The columns correspond to treatments shown on the $\mathrm{C} 1 \mathrm{~s}$ spectra in the left-hand plate of Figure 7. The selectivity patterns after pretreatment with $\mathrm{nH}$ only are also similar: much hexene and benzene and low amounts of saturated $\mathrm{C}_{6}$ products were formed. Hexene selectivity increased at the expense of fragmentation after pretreatment with much $\mathrm{H}_{2}$. Except for treatments with $\mathrm{nH}$ alone, the peak maxima of the $\mathrm{C} 1 \mathrm{~s}$ difference spectra do not agree with those of the actual $\mathrm{C}$ 1s lines, pointing to the different abundance of $\mathrm{C} 1 \mathrm{~s}$ components after treatments at 483 and $603 \mathrm{~K}$. Somewhat more graphitic carbon was formed at $603 \mathrm{~K}$. The smallest difference (and the lowest $\mathrm{C}$ $1 \mathrm{~s}$ peaks) appeared after pretreatment in the presence of $320 \mathrm{mbar}_{2}$. The relative abundance of the "PtC" component (BE $\sim 283.5 \mathrm{eV}$ ) and, perhaps, also that of the "chain" carbon (BE $\sim 284.1 \mathrm{eV}$ ) was lower after the lowtemperature deactivation. Deactivation at $603 \mathrm{~K}$ produced somewhat more graphite plus " $\mathrm{C}_{\mathrm{x}} \mathrm{H}_{\mathrm{y}}$ " $(\mathrm{BE} \sim 284.6 \mathrm{eV}$ and $\sim 285.6 \mathrm{eV}$ ). These latter species actually appear in the fitted difference spectra "603-483 K" (Figure 9 in Ref. [26]). The "chain C": (BE $~ 284.1 \mathrm{eV})$ is missing from these difference spectra, but appears in the other two difference spectra $\left(\mathrm{nH}=53\right.$ mbar, $\mathrm{nH}: \mathrm{H}_{2}=13: 320$ mbar). Pt pretreated at $483 \mathrm{~K}$ retained not twice, but three times more activity than the other sample and a spectacular drop of hexene selectivity with parallel higher isomer selectivity was seen over this sample. Accordingly, graphite and $\mathrm{C}_{\mathrm{x}} \mathrm{H}_{\mathrm{y}}$ caused stronger deactivation than the other $\mathrm{C} 1 \mathrm{~s}$ components. The hydrogen excess at $483 \mathrm{~K}$ was sufficient to prevent accumulation of some two-dimensional carbon and keep more hydrogen-saturated $\mathrm{Pt}$ surface suitable for $\mathrm{C}_{5}$-cyclization and subsequent isomerization.

Combined electron spectroscopic and catalytic experiments helped us to quantify the well-known fact of deactivation by carbon accumulation. Figure 8 depicts results adapted from Refs. [26] and [48]. Regenerated Pt contained $10-16 \%$ Pt. Small activity loss $(20-25 \%)$ is seen in the presence of $20-24 \% \mathrm{C}$. Increasing the carbon content from 24 to ca. $28 \%$ resulted in an abrupt decrease of the 

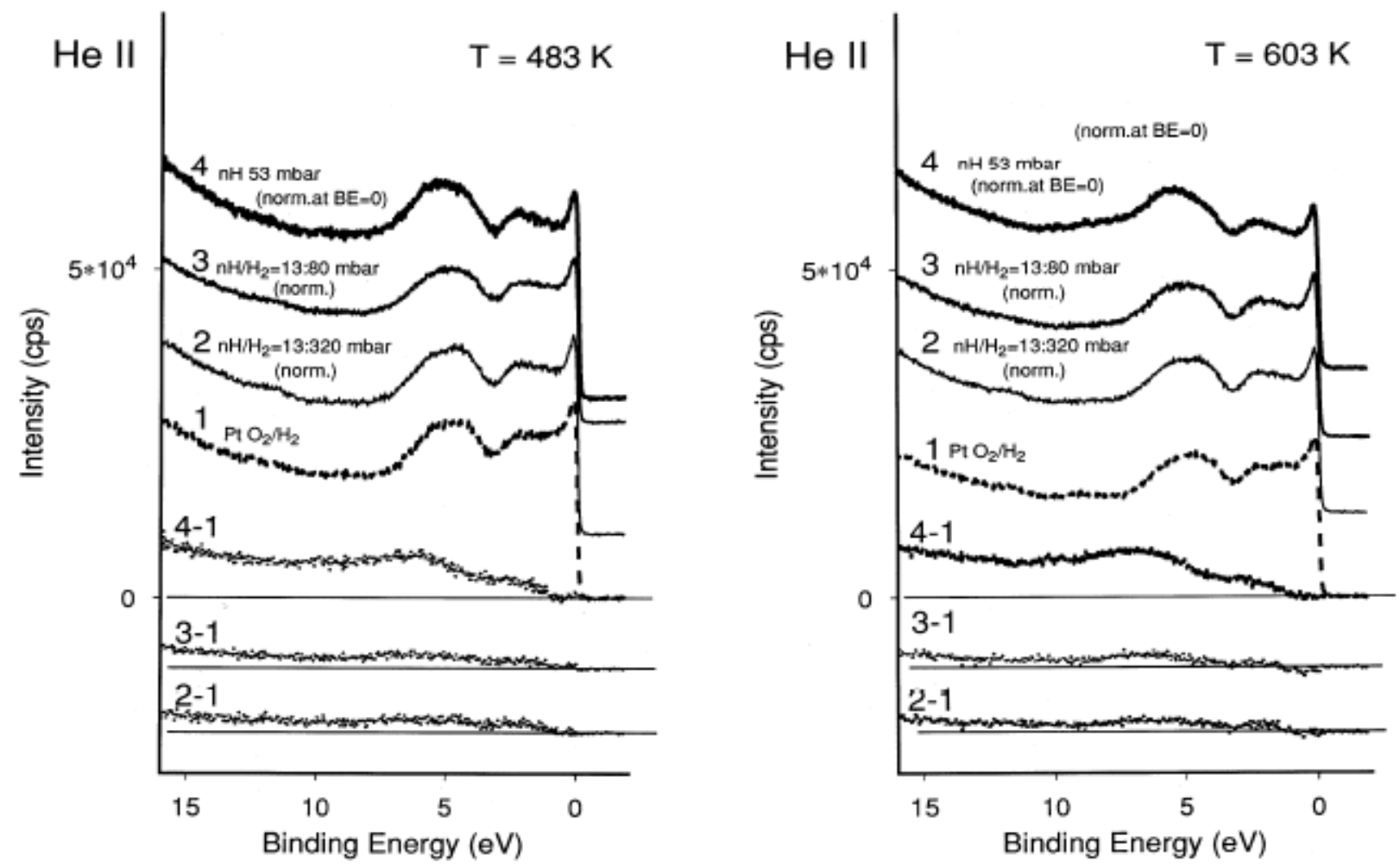

Fig. 6: He II spectra after deactivating treatments at 483 and $603 \mathrm{~K}$, normalized at the Fermi-edge, and their difference spectra.
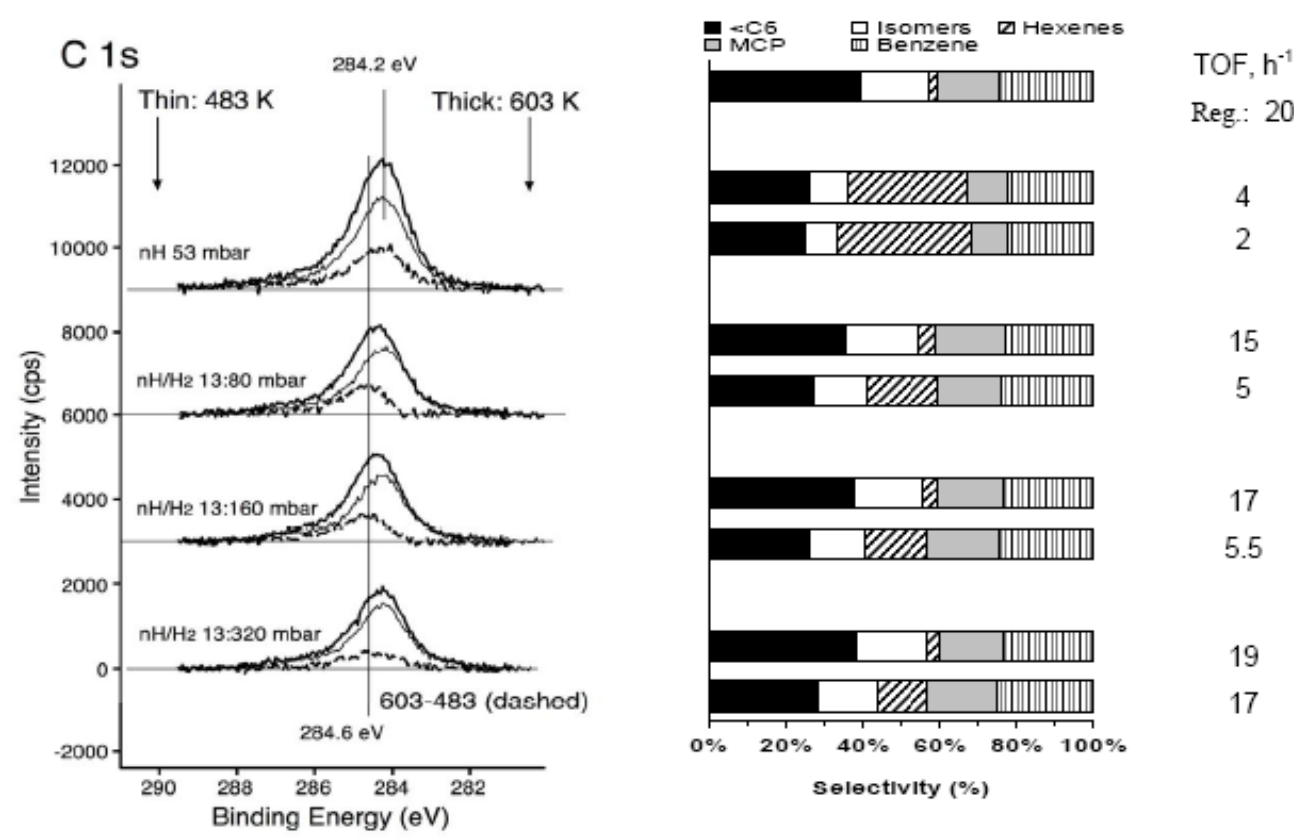

Fig. 7: Left-hand plate: $\mathrm{C} 1 \mathrm{~s}$ peaks and their difference measured on Pt blacks subjected to different deactivating treatments (as shown on the figure). C content: 28 and $35 \%$ after treatments without $\mathrm{H}_{2}$ (at 483 and $603 \mathrm{~K}$, respectively), 21-26\% after treatments with $\mathrm{nH}+\mathrm{H}_{2}$.

Right-hand plate: Selectivities of hexane transformation in test runs $\left(603 \mathrm{~K}, \mathrm{nH}: \mathrm{H}_{2}=13: 160 \mathrm{mbar}\right)$ after the same treatments. The columns follow the sequence of the left-hand plate, the upper column of the pair shows selectivities after a treatment at $483 \mathrm{~K}$, the lower after $603 \mathrm{~K}$. Adapted partly after Ref. [26]. 


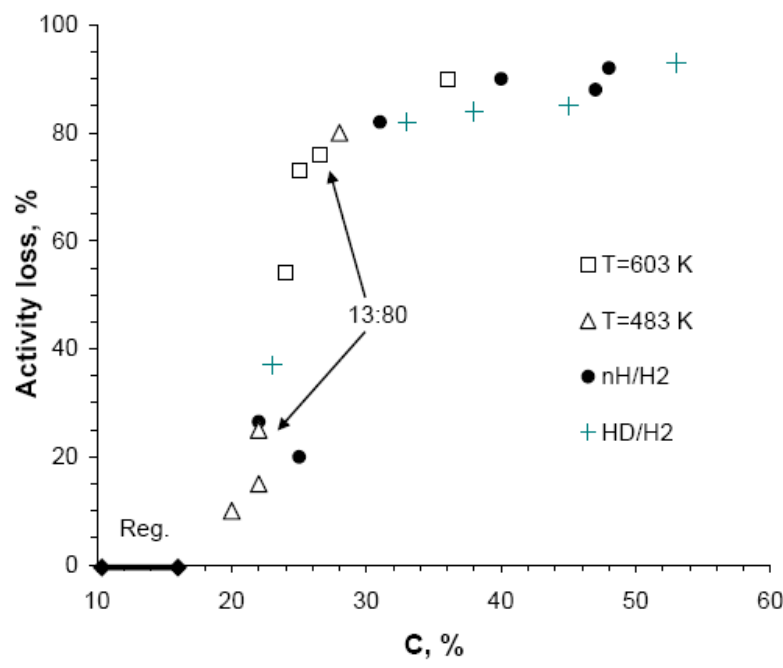

Fig. 8: The loss of overall activity in test runs after deactivating treatments as a function of the carbon percentage measured from the C 1s line. Symbols: $\square$ and $\Delta$ after Ref. [26], pretreatments with $\mathrm{nH}$ or $\mathrm{nH}: \mathrm{H}_{2} ; \bullet$ and + after Ref. [48], treatments, as shown.

initial activity. The $\mathrm{C} \%$ could thereafter increase up to $55 \%$ with the parallel activity loss being in the range of 80 $90 \%$. The points denoted by arrow revealing the large difference after the same pretreatment $\left(\mathrm{nH}: \mathrm{H}_{2}=13: 80\right.$ mbar) applied at 483 and $603 \mathrm{~K}$. The threefold drop of activity after pretreatment at $603 \mathrm{~K}$ was accompanied by a threefold increase of the hexene selectivity (Figure 7) at the expense of isomers and fragments. It is the amount of carbon causing the dramatic activity drop in the range of $20-30 \% \mathrm{C}$, since the distribution of $\mathrm{C} 1 \mathrm{~s}$ component after fitting do not show dramatic differences. Thus, deactivation is caused by carbon occupying a higher proportion of Pt surface, with two consequences: (1) the number of active sites (or more correctly: active ensembles [49]) decreases, leading to the loss of 2/3 of the catalytic activity; (2) reactions requiring multiple sites (fragmentation) or much surface hydrogen (isomerization) [42] are suppressed. As the severity of pretreatment increased, the former effect prevailed, but fragmentation and aromatization still found their ensembles. The activity, however, also decreased [26] in this sequence by almost an order of magnitude, thus the number of active ensembles actually present was rather low. XPS results (Figure 7) show, however, that the chemical state of carbon affects mainly selectivities.

\subsection{Other related studies with Pt-based cata- lysts}

The use of Pt black is an exception rather than common practice in present-day catalytic research. We extended our electron spectroscopic studies also to supported catalysts. The most common oxide supports $\left(\mathrm{Al}_{2} \mathrm{O}_{3}\right.$ or $\mathrm{SiO}_{2}$ ) are insulators, therefore they become electrostatically charged in the spectrometer, causing shift in the peak BE values and line broadening [50,51]. This latter can be eliminated by the use of flood gun, but calibration to a well-known peak can also be sufficient in the absence of inhomogeneous electrostatic charges. TUBUS experiments can be used against this latter phenomenon (when the metal particles become different charge than the support). This treatment applies a potential to the lens entrance device kept, as a rule, at ground potential. It adds positive or negative charge to the existing charge. When this effect brings about line shape change, then inhomogeneous charge is present [51]. Such a phenomenon occurred on EUROPT-1 (a standard $6 \% \mathrm{Pt} / \mathrm{SiO}_{2}$ catalyst [52]), in both oxidized and reduced state [50] and after sulfidation [51]. This effect was, however, missing on Pt/sulfated zirconia catalyst [53]. XPS revealed that some sulfate groups could be reduced and form PtS (appearing as $\mathrm{S}^{2-}$ ) upon reduction [54]. On the contrary, some of the sulfur in Pt sulfided with $\mathrm{H}_{2} \mathrm{~S}$ can be oxidized to $S^{4+}$ and/or $S^{6+}[55,56]$. Sulfate represents a general catalyst poison: all activity except hexene formation requiring single $\mathrm{Pt}$ atoms is poisoned. Sulfide, in turn is a selective poison hindering aromatization (on threeatom ensembles) [56]. This occurred also with reduced $\mathrm{Pt} /$ sulfated zirconia catalyst [54].

Carbon (graphite nanofiber, GNF) support is an electric conductor, thus, no charging effects appear. XPS of Pt/GNF catalysts (with GNF of different structures [57]) permitted to draw essentially the same conclusions as the measurements with $\mathrm{Pt}$ black. Carbonization of $\mathrm{Pt}$, of course, could not be monitored, but removal of small amounts of surface $\mathrm{PtO}$ upon $\mathrm{H}_{2}$ treatment was observed. Graphite nanofiber has a hydrogen storage capacity, thus "reverse spillover" keeps the Pt surface rich in hydrogen. Therefore reactions requiring hydrogen-rich sites (isomerization, and $\mathrm{C}_{5}$-cyclization of hexane) were promoted. Corruption of the graphite structure led to depletion of surface Pt and lower catalytic activity.

\section{Possible directions for future research.}

The measurements described so far can be called "quasi-in-situ". Spectroscopy and catalysis were separated in time and space. The lifetime of the experimental setup making exposures of the catalyst to vapors at elevated temperatures in the spectrometer has ended. It did what it could do in revealing correlations between catalyst characterization and catalytic properties, but the time has arrived to continue these studies with more modern equipments. Of the underlying ideas stressed in the present review, one will certainly survive: namely that the catalyst and the reactants represent a dynamic system. Surface and subsurface regions of the solid catalyst both play some role in producing the active catalyst [47]. For example, both XPS and UPS showed rather marked $\mathrm{Pd}-\mathrm{C}$ interactions (lattice dilatation, drop of density of surface states) after ethene and $\mathrm{H}_{2}$ (in low excess) were contacted with Pd black [58,59]. These papers present indication rather than evidence on such interactions but the importance of "real in-situ techniques, 
such as a specially built high-pressure XPS" is pointed out as a final conclusion (Ref. [59], last sentence). These experiments have already started in the Department of Inorganic Chemistry of the FHI: the new generation of instruinstruments will be operated by a new generation of scientists. The detailed summary of the new results is far beyond the scope of the present review, just some initial results will be mentioned.

A "new paradigm" was postulated for alkyne hydrogenation [60]. Briefly, it has been shown that the selective hydrogenation of the $\mathrm{C} \equiv \mathrm{C}$ triple bond takes place on a "PdC surface phase", rather than on pure Pd metal. This phase is formed during reaction. By changing the excitation energy, in-situ XPS could produce bulk sensitive and surface sensitive pictures of the Pd $3 d$ line showing a special metastable $-\mathrm{Pd}-\mathrm{C}$ component in the near-surface region. Different crystal facets have different ability to dissolve carbon: if, instead of $\mathrm{Pd}-\mathrm{C}$ phase, a $\mathrm{Pd}-\mathrm{H}$ phase is favored, total hydrogenation to alkane occurs. Another new technique is the application of prompt-gamma activation analysis (PGAA) [61]. This technique is sensitive to hydrogen and was successfully used to determine the hydrogen content of Pt catalysts [62]. Direct in-situ determination of hydrogen by PGAA in during pentyne hydrogenation over Pd black catalyst [63] (gas phase $\mathrm{H}_{2}$ background being negligible) gave $\mathrm{H} / \mathrm{Pd}$ ratios of 0.86 as an average during experiments. Nonselective hydrogenation to pentane occurred when the $\mathrm{Pd} / \mathrm{H}$ ratio was high $(0.76-0.92)$ whereas selective hydrogenation to pentenes took place with $\mathrm{H} / \mathrm{Pd}$

\section{References}

[1] J. J. Berzelius, Annals. Chim. Phys. 61 (1836) 146.

[2] V. Ponec, G. C. Bond, Catalysis by Metals and Alloys, Studies in Surface Science and Catalysis, Vol. 95, Elsevier, Amsterdam, 1995.

[3] G. Ertl, J. Küppers, Low Energy Electrons and Surface Chemistry, VCH, Weinheim, 1974.

[4] R. Imbihl, J. R. Behm, G. Ertl, W. Moritz, Surface Sci. 123 (1982) 129

[5] G. Ertl, Journal of Vacuum Science and Technology, A1 (1983) 1247.

[6] G. Ertl, M. Huber, S. B. Lee, Z. Paál, M. Weiss, Appl. Surf. Sci. 8 (1981) 373

[7] Catalytic Naphtha Reforming (G. J. Antos, A. M. Aitani, J. M. Parera Eds.) Marcel Dekker, 1995; Second Edition, (G. J. Antos, A. M. Aitani, Eds.) Marcel Dekker, 2004.

[8] H. P. Bonzel, Surface Sci., 68 (1977) 236.

[9] G. A. Somorjai, Adv. Catal. 26 (1977) 1.

[10] Z. Paál, Adv. Catal. 29 (1980) 273.

[11] F. G. Gault, Adv. Catal. 30 (1981) 1.

[12] Z. Paál. P. Tétényi, J. Catal. 30 (1973) 350.

[13] O. Loew, Ber. Dtsch. Chem. Ges. 23 (1890) 289.

[14] C. Paal, Berichte 49 (1916) 548.

[15] (a) T. Baird, Z. Paál, S. J. Thomson, J. Chem, Soc. Faraday Trans. I, 69 (1973) 50; (b) T. Baird, Z. Paál, S. J. Thomson, J. Chem, Soc. Faraday Trans. I, 69 (1973) 1273.

[16] D. J. O'Rear, D. G Löffler, M. Boudart, J. Catal. 94 (1985) 225. being 0.18 . The $\mathrm{H} / \mathrm{Pd}$ ratio depended first of all on the prehistory of sample, the buildup of $\mathrm{Pd}-\mathrm{C}$ phase being a slow process, as opposed to the rapid dissolution of $\mathrm{H}$ in $\mathrm{Pd}$. This rate difference may have led to temporal fluctuations of selective and nonselective hydrogenation. The results were consistent with the Pd $3 d$ spectra measured with highpressure XPS.

These are just a few new directions towards the understanding of catalysis on the molecular level: the milestones of which bear the name of G. Ertl, from ordered chemisorption [17] to spatiotemporal patterns [64]

\section{Acknowledgements}

The authors thank first of all Prof. G. Ertl for making the start of these studies possible and for his actual participation in the initial stages of research, resulting in two publications. We also thank all co-authors in Berlin, Budapest and other cities for their active participation in experimental work and their evaluation as well as for their contribution in preparing the final form of the present paper. Special thanks are due to Prof. M. Muhler, Ms. U. Wild, Dr. W. Vogel, Dr. J. Find, Dr. T. Ressler, Mr. H. Sauer as well as Dr. A. Wootsch, Dr. D. Teschner, Dr. N. Győrffy.

[17] K. Christmann, G. Ertl, T. Pignet, Surface Science 54 (1976) 365.

[18] Z. Paál, S. J. Thomson, J. Catal. 90 (1973) 96.

[19] P. A. Sermon, J. Catal., 24 (1972) 460; 467.

[20] Z. Paál, X. L. Xu, J. Paál-Lukács, W. Vogel, M. Muhler, R. Schlögl, J. Catal. 152 (1995) 252.

[21] G. Maire, F. Berhardt, P. Légaré, G. Lindauer I, Proc. $7^{\text {th }}$ In. Vacuum Congr. \& $3^{\text {rd }}$ Int. Conf. Solid Surfaces, Vienna, 1977, p. 861.

[22] Z. Paál, U. Wild, A. Wootsch, J. Find, R. Schlögl, Phys. Chem. Chem. Phys. 3 (2001) 2148.

[23] J. Find, Z. Paál, U. Wild, R. Schlögl, Catal. Lett., 65 (2000) 19.

[24] N. M. Rodriguez, P. E. Anderson, A. Wootsch, U. Wild, R. Schlögl, Z. Paál, J. Catal., 197 (2001) 365.

[25] Z. Paál, Z. Zhan, E. Fülöp, B. Tesche, J. Catal., 1567 (1995) 19.

[26] Z. Paál, A. Wootsch, I. Bakos, S. Szabó, H. Sauer, U. Wild, R. Schlögl, Appl. Catal. A: General, 309 (2006) 1.

[27] Z. Paál, in Hydrogen Effect in Catalysis, (Paál, Z., Menon, P. G., Eds.) Marcel Dekker, New York, 1988, p. 293 and references therein.

[28] Z. Paál, P. Tétényi, D. Prigge, X. Zh. Wang, G. Ertl, Appl. Surf. Sci. 14 (1982-83) 307.

[29] Z. Paál, R. Schlögl, G. Ertl, Catal. Lett., 12 (1992) 331.

[30] Z. Paál, R. Schlögl, G. Ertl, J. Chem. Soc. Faraday Trans., 88 (1992) 1179. 
[31] Z. Paál, R. Schlögl, Surf. Interf. Anal., 19 (1992) 524.

[32] Z. Paál, M. Muhler, R. Schlögl, Surface Science Spectra, 4 (1997) 119.

[33] Z. Paál, H. Zimmer, J. R. Günter, R. Schlögl, M. Muhler, J. Catal. 119 (1989) 146.

[34] Z. Paál, Z. Zhan, Langmuir, 13 (1997) 3752.

[35] K. S. Kim, N. Winograd, R. E. Davis, J. Am. Chem. Soc., 93 (1971) 6296.

[36] D. M. Collins, W. E. Spicer, Surf. Sci., 69 (1977) 114.

[37] (a) A. Sárkány, Catal. Today 5 (1989) 173; (b) A. Sárkány, J. Chem. Soc. Faraday Trans., 85 91989) 1523.

[38] S. J. Thomson, G. Webb, J. Chem. Soc. Chem. Comm., (1976) 526

[39] G. A. Somorjai, F. Zaera, J. Phys. Chem., 86 (1982) 3070.

[40] P. G. Menon, J. Mol. Catal., 59 (1990) 207.

[41] G. A. Somorjai, Introduction to Surface Chemistry and Catalysis, Wiley, New York, 1994.

[42] Z. Paál, Chapter 2 in Ref. [Fehler! Textmarke nicht definiert.].

[43] P. Biloen, J. N. Helle, H. Verbeek, F. M. Dautzenberg, and W. M. H. Sachtler, J. Catal., 63 (1980) 112.

[44] G. A Somorjai, Proc. $8^{\text {th }}$ Internat. Congr. Catalysis, Berlin, 1984, VCH, Weinheim, 1984, Vol. 1, p. 113.

[45] A. Wootsch, Z. Paál, N. Győrffy, S. Ello, I. Boghian, J. Leverd, L. Pirault-Roy, J. Catal. 238 (2006) 67.

[46] J. Find, Z. Paál, H. Sauer, R. Schlögl, U. Wild, A. Wootsch, Studies in Surface Sci. Catal., Vol 130. (A. Corma, F. V. Melo, S. Mendioroz, J. L. G. Fierro, Eds.) Elsevier, Amsterdam, 2000, p. 2291.

[47] G. A. Somorjai, J. Mol. Catal. A, 107 (1996) 369.

[48] Z. Paál, A. Wootsch, R. Schlögl, U. Wild, Appl. Catal. 252 (2005) 135.

[49] M. Boudart. Adv. Catal. 20 (1969), 153.
[50] M. Muhler, Z. Paál. R. Schlögl, Appl. Surface Sci., 41 (1991) 281.

[51] Z. Paál, M. Muhler, R. Schlögl, J. Catal. 143 (1993) 318.

[52] Z. Paál, G. C. Bond, Appl. Catal. 86 (1992) 1.

[53] M. Manoli, C. Potvin, M. Muhler, U. Wild, G. Resofszki, T. Buchholz, Z. Paál, J. Catal. 178 (1998) 338.

[54] M.-D. Appay, J.-M. Manoli, C. Potvin, M. Muhler, U. Wild, O. Pozdnyakova, Z. Paál, J. Catal., 222 (2004) 419.

[55] Z. Paál, K. Matusek, M. Muhler, Appl. Catal. A, 149 (1997) 113.

[56] Z. Paál, M. Muhler, K. Matusek, J. Catal. 175 (1998) 245.

[57] R. T. K. Baker, N. Rodriguez, A. Mastalir, U. Wild, R. Schlögl, A. Wootsch, Z. Paál, J. Phys. Chem. B, 108 (2004) 14348.

[58] Z. Paál, U. Wild, R. Schlögl, Phys. Chem. Chem. Phys., 3 (2001) 4644.

[59] D. Teschner, U. Wild, R. Schlögl, Z. Paál, J. Phys. Chem. B, 109 (2005) 20516.

[60] D. Teschner, E. Vass, M. Hävecker, S. Zafeiratos, P. Schnörch, H. Sauer, A. Knop-Gericke, R. Schlögl, M. Chamam, A. Wootsch, A. S. Canning, J. J. Gammann, S. D. Jackson, J. McGregor, L. F. Gladden, J. Catal. 242 (2006) 26.

[61] G. Molnár (Ed.) Handbook of Prompt Gamma Activation Analysis with Neutron Beams Kluwer, Dordrecht, 2004

[62] Z. Kasztovszky, Z. Révay, G. Molnár, A. Wootsch, Z. Paál, Catal. Comm. 3 (2002) 553.

[63] D. Teschner, J. Borsodi, A. Wootsch, Z. Révay, M. Hävecker, A. Knop-Gericke, S. D. Jackson, R. Schlögl, Science, 320 (2008) 86.

[64] R. Imbihl, G. Ertl, Chem. Rev., 95 (1995) 697. 